\title{
RESPIRATORY TUBERCULOSIS IN THE BIRMINGHAM REGION*
}

\author{
BY \\ P. G. ARBLASTTER, K. W. CROSS, AND V. H. SPRINGETT \\ From the Regional Hospital Board, Birmingham
}

With the introduction of the National Health Service in Great Britain in 1948, the Birmingham Regional Hospital Board was formed with responsibility for diagnostic and treatment services for a population of almost four and a half million distributed over five administrative counties and ten county boroughs in the West Midland area of England. With regard to tuberculosis, the Regional Hospital Board became responsible for specialist and hospital services, while prevention and after-care remained the responsibility of the fifteen local health authorities (the counties and county boroughs). The medical care of the patient at home was the responsibility of the third branch of the Service, the general practitioner. The object of this report is to review the changes that have occurred in all aspects of tuberculosis in the 10 years since the introduction of the National Health Service.

\section{Methods in Use in the Post-War Period}

In 1948 the standard method of treatment of pulmonary tuberculosis was a period of rest and graduated exercise in a sanatorium. For cavitated disease that was not extensive, collapse measures were an important part of treatment: collapse might be either temporary, in the form of artificial pneumothorax or pneumoperitoneum requiring air refills at weekly or fortnightly intervals for 2-3 years, or permanent, by major surgery in the form of thoracoplasty or some modification of this procedure.

On the preventive side, the main emphasis lay in the improvement of living conditions, both generally and for the household contacts of known cases of tuberculosis. Intensive and repeated examinations of contacts were necessary to find cases in the earliest possible stages, and mass radiography had been

* A report prepared for the Regional Advisory Committee on Tuberculosis Services of the Birmingham Regional Hospital Board. introduced a few years earlier in a further attempt to find cases with disease of limited extent, and to identify unknown sources of infection in the community.

\section{Methods Introduced in Past 10 Years}

The most important change in treatment has been the introduction of drugs effective against tubercle bacilli. Streptomycin was first made available on an experimental basis in 1947, and was followed shortlyo by para-amino-salicyclic acid (P.A.S.). These remained standard treatment until the introduction of the probably even more effective drug isoniazid in the early part of 1952 . The efficacy of these drugs in the treatment of tuberculosis led to demonstrable improvements in some aspects of tuberculosis control, and also made possible other methods of treatment for some patients, including surgical removal of diseased portions of lung. It is largely the influence of this new method of treatment by drugs on other aspects of tuberculosis work that is reviewed here.

On the preventive side, vaccination with B.C.G. was introduced into this region in 1949 for those exposed to special risk of infection, e.g. household contacts and hospital workers, and from 1954 local health authorities have been empowered to introduce schemes of vaccination for schoolchildren between their thirteenth and fourteenth birthdays.

\section{Epidemiology ANd Prevention}

MorTaLITY.- It is well known that deaths from pulmonary tuberculosis have decreased dramatically in recent years. The trends in this Region in death rates per million population for each of five age groups are shown in Fig. 1 (opposite) for men and women respectively, and these rates are also given in Table I (opposite). 

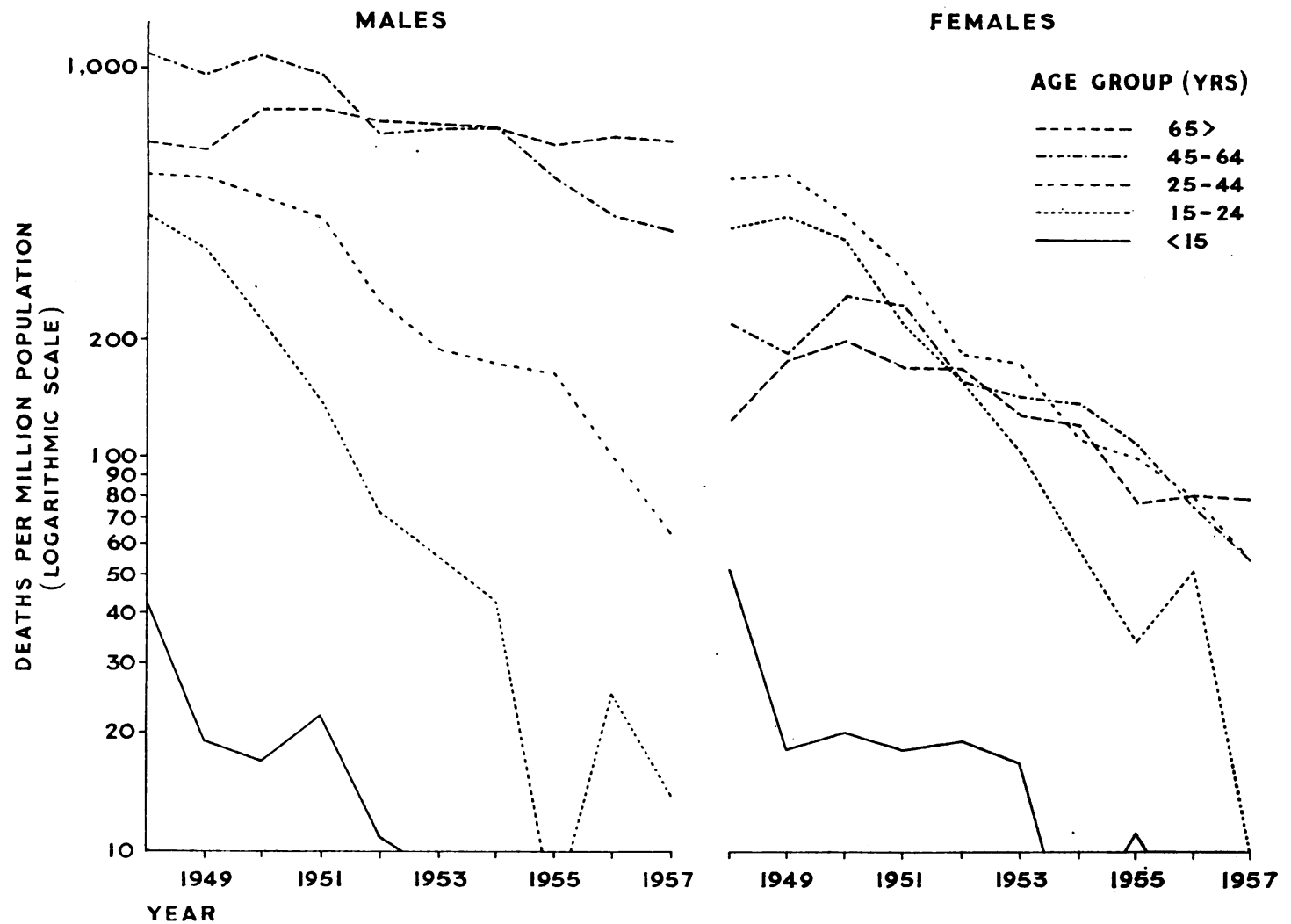

FIG. 1.-Deaths per million population, by sex and age group.

TABLE 1

RESPIRATORY TUBERCULOSIS MORTALITY IN THE BIRMINGHAM REGION (1948-57), BY SEX AND AGE ANNUAL NUMBER OF DEATHS PER MILLION POPULATION

\begin{tabular}{|c|c|c|c|c|c|c|c|c|c|c|c|c|c|c|}
\hline \multirow{3}{*}{ Year } & \multicolumn{12}{|c|}{ Age (years) } & \multirow{2}{*}{\multicolumn{2}{|c|}{$\begin{array}{l}\text { No. of Deaths } \\
\text { (all ages) }\end{array}$}} \\
\hline & \multicolumn{2}{|c|}{ Under 15} & \multicolumn{2}{|c|}{$15-24$} & \multicolumn{2}{|c|}{$25-44$} & \multicolumn{2}{|c|}{$45-64$} & \multicolumn{2}{|c|}{65 and Over } & \multicolumn{2}{|c|}{ All Ages } & & \\
\hline & Male & Female & Male & Female & Male & Female & Male & Female & Male & Female & Male & Female & Male & Female \\
\hline $\begin{array}{l}1948 \\
1949 \\
1950 \\
1951 \\
1952 \\
1953 \\
1954 \\
1955 \\
1956 \\
1957\end{array}$ & $\begin{array}{r}44 \\
19 \\
17 \\
22 \\
11 \\
9 \\
7 \\
0 \\
4 \\
2\end{array}$ & $\begin{array}{r}52 \\
18 \\
20 \\
18 \\
19 \\
17 \\
4 \\
11 \\
0 \\
0\end{array}$ & $\begin{array}{r}411 \\
345 \\
226 \\
139 \\
72 \\
56 \\
42 \\
7 \\
25 \\
14\end{array}$ & $\begin{array}{r}391 \\
418 \\
358 \\
220 \\
163 \\
105 \\
58 \\
34 \\
51 \\
10\end{array}$ & $\begin{array}{r}530 \\
522 \\
468 \\
406 \\
259 \\
191 \\
172 \\
162 \\
101 \\
64\end{array}$ & $\begin{array}{r}521 \\
533 \\
418 \\
306 \\
188 \\
175 \\
115 \\
100 \\
81 \\
55\end{array}$ & $\begin{array}{r}1,058 \\
965 \\
1,097 \\
952 \\
688 \\
700 \\
686 \\
521 \\
417 \\
380\end{array}$ & $\begin{array}{r}220 \\
185 \\
261 \\
242 \\
161 \\
146 \\
140 \\
110 \\
78 \\
54\end{array}$ & $\begin{array}{l}647 \\
606 \\
785 \\
791 \\
739 \\
711 \\
689 \\
625 \\
672 \\
645\end{array}$ & $\begin{array}{r}126 \\
179 \\
201 \\
169 \\
169 \\
130 \\
122 \\
78 \\
81 \\
79\end{array}$ & $\begin{array}{l}522 \\
482 \\
490 \\
429 \\
310 \\
287 \\
276 \\
224 \\
189 \\
167\end{array}$ & $\begin{array}{r}288 \\
284 \\
260 \\
199 \\
138 \\
118 \\
89 \\
71 \\
58 \\
39\end{array}$ & $\begin{array}{r}1,325 \\
1,136 \\
1,067 \\
929 \\
675 \\
630 \\
607 \\
496 \\
422 \\
374\end{array}$ & $\begin{array}{r}776 \\
770 \\
585 \\
450 \\
312 \\
269 \\
204 \\
164 \\
134 \\
92\end{array}$ \\
\hline
\end{tabular}

A rapidly decreasing trend is evident for each age group and each sex, with the exception of men aged 65 years and over; the 1956 rate for this age group is greater than those for 1948 and 1949 , although a gradual decrease has taken place since 1951.

Some deaths from tuberculosis occur in persons not notified before death. Figures for the Region as a whole are not available, but the number of such cases each year in the City of Birmingham (pop. $1,110,000)$ has shown no tendency to fall, and the position in the Region as a whole is probably little different. Such deaths have amounted to about 4 per cent. of notifications in Birmingham. 


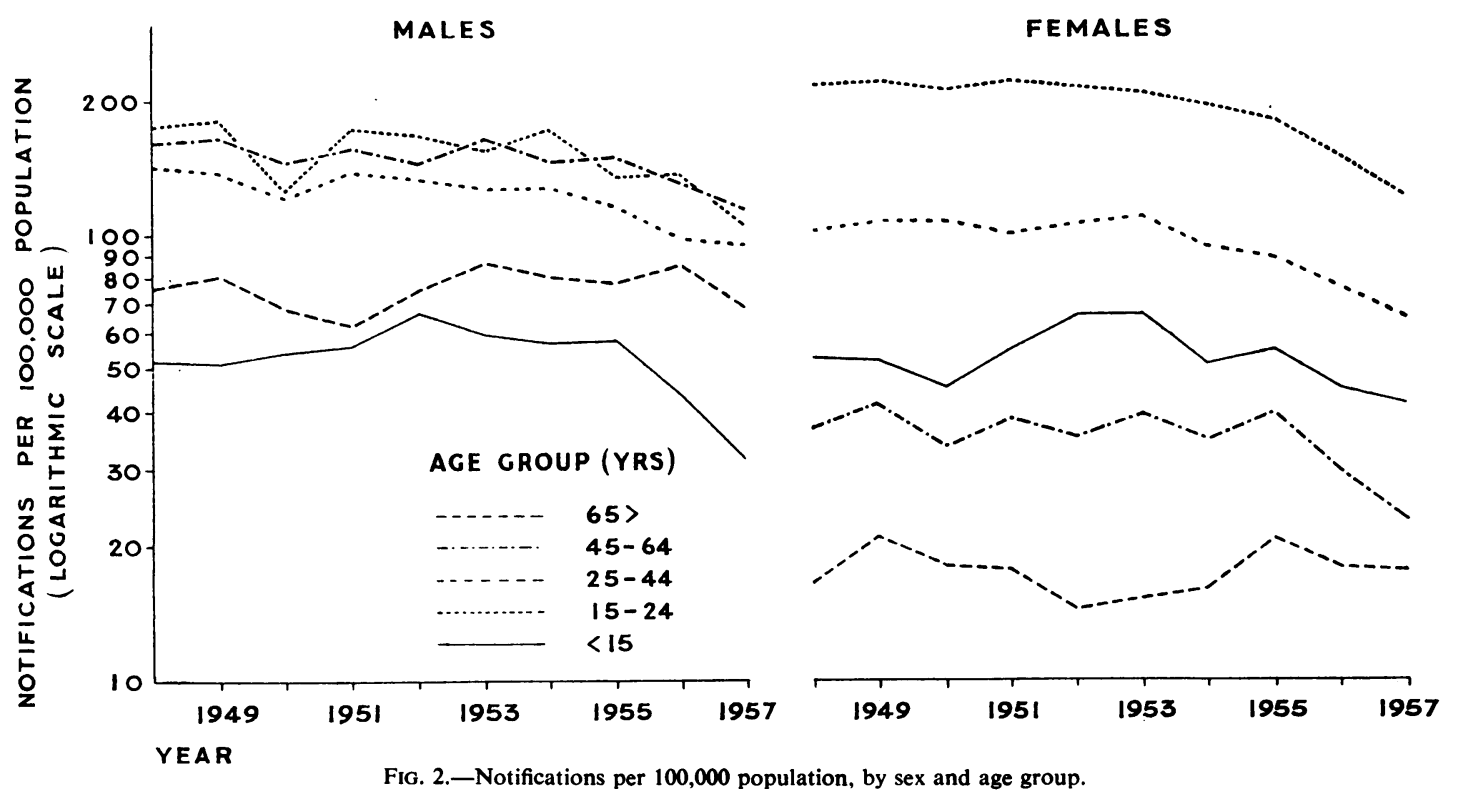

TABLE II

RESPIRATORY TUBERCULOSIS NOTIFICATION RATES PER 100,000 POPULATION IN THE BIRMINGHAM REGION (1948-57), BY SEX AND AGE

\begin{tabular}{|c|c|c|c|c|c|c|c|c|c|c|c|c|c|c|}
\hline \multirow{3}{*}{ Year } & \multicolumn{12}{|c|}{ Age (years) } & \multirow{2}{*}{\multicolumn{2}{|c|}{$\begin{array}{l}\text { Number of } \\
\text { Notifications } \\
\text { (all ages) }\end{array}$}} \\
\hline & \multicolumn{2}{|c|}{ Under 15} & \multicolumn{2}{|c|}{$15-24$} & \multicolumn{2}{|c|}{$25-44$} & \multicolumn{2}{|c|}{$45-64$} & \multicolumn{2}{|c|}{65 and Over } & \multicolumn{2}{|c|}{ All Ages } & & \\
\hline & Male & Female & Male & Female & Male & Female & Male & Female & Male & Female & Male & Female & Male & Female \\
\hline $\begin{array}{l}1948 \\
1949 \\
1950 \\
1951 \\
1952 \\
1953 \\
1954 \\
1955 \\
1956 \\
1957\end{array}$ & $\begin{array}{l}51 \cdot 8 \\
51 \cdot 1 \\
54 \cdot 5 \\
56 \cdot 0 \\
66 \cdot 5 \\
59 \cdot 1 \\
57 \cdot 4 \\
58 \cdot 2 \\
43 \cdot 8 \\
31 \cdot 1\end{array}$ & $\begin{array}{l}52 \cdot 5 \\
52 \cdot 4 \\
45 \cdot 0 \\
55 \cdot 3 \\
65 \cdot 4 \\
65 \cdot 4 \\
50 \cdot 9 \\
55 \cdot 5 \\
45 \cdot 4 \\
41 \cdot 5\end{array}$ & $\begin{array}{l}178 \cdot 9 \\
181 \cdot 0 \\
126 \cdot 0 \\
170 \cdot 8 \\
168 \cdot 3 \\
155 \cdot 1 \\
173 \cdot 9 \\
135 \cdot 7 \\
137 \cdot 5 \\
108 \cdot 5\end{array}$ & $\begin{array}{l}215 \cdot 1 \\
222 \cdot 3 \\
211 \cdot 1 \\
221 \cdot 4 \\
218 \cdot 0 \\
209 \cdot 5 \\
196 \cdot 6 \\
181 \cdot 6 \\
152 \cdot 4 \\
123 \cdot 8\end{array}$ & $\begin{array}{r}143 \cdot 5 \\
138 \cdot 3 \\
123 \cdot 0 \\
139 \cdot 5 \\
134 \cdot 9 \\
129 \cdot 1 \\
129 \cdot 7 \\
115 \cdot 6 \\
99 \cdot 7 \\
95 \cdot 0\end{array}$ & $\begin{array}{r}102 \cdot 3 \\
108 \cdot 9 \\
108 \cdot 5 \\
99 \cdot 9 \\
106 \cdot 1 \\
112 \cdot 4 \\
93 \cdot 2 \\
88 \cdot 0 \\
76 \cdot 6 \\
65 \cdot 6\end{array}$ & $\begin{array}{l}164 \cdot 0 \\
164 \cdot 4 \\
147 \cdot 2 \\
158 \cdot 1 \\
146 \cdot 8 \\
161 \cdot 8 \\
145 \cdot 8 \\
151 \cdot 4 \\
132 \cdot 2 \\
113 \cdot 4\end{array}$ & $\begin{array}{l}36 \cdot 6 \\
41 \cdot 5 \\
33 \cdot 3 \\
38 \cdot 4 \\
35 \cdot 0 \\
39 \cdot 9 \\
34 \cdot 3 \\
39 \cdot 7 \\
29 \cdot 3 \\
22 \cdot 3\end{array}$ & $\begin{array}{l}74 \cdot 9 \\
81 \cdot 0 \\
68 \cdot 0 \\
61 \cdot 6 \\
75 \cdot 6 \\
87 \cdot 8 \\
80 \cdot 3 \\
78 \cdot 3 \\
86 \cdot 0 \\
68 \cdot 8\end{array}$ & $\begin{array}{l}16 \cdot 7 \\
21 \cdot 3 \\
18 \cdot 0 \\
17 \cdot 7 \\
14 \cdot 5 \\
15 \cdot 4 \\
16 \cdot 0 \\
20 \cdot 5 \\
17 \cdot 9 \\
17 \cdot 5\end{array}$ & $\begin{array}{r}124 \cdot 6 \\
123 \cdot 6 \\
112 \cdot 1 \\
120 \cdot 6 \\
120 \cdot 0 \\
119 \cdot 2 \\
117 \cdot 3 \\
109 \cdot 5 \\
97 \cdot 2 \\
83 \cdot 0\end{array}$ & $\begin{array}{l}81 \cdot 5 \\
86 \cdot 0 \\
80 \cdot 4 \\
82 \cdot 4 \\
84 \cdot 5 \\
86 \cdot 3 \\
74 \cdot 1 \\
73 \cdot 2 \\
60 \cdot 6 \\
51 \cdot 0\end{array}$ & $\begin{array}{l}2,635 \\
2,662 \\
2,440 \\
2,613 \\
2,612 \\
2,614 \\
2,578 \\
2,422 \\
2,167 \\
1,863\end{array}$ & $\begin{array}{l}1,793 \\
1,926 \\
1,808 \\
1,859 \\
1,915 \\
1,964 \\
1,699 \\
1,685 \\
1,403 \\
1,190\end{array}$ \\
\hline
\end{tabular}

Notifications.-The regional trends over the years $1948-57$ in the notification rates per 100,000 population in each age group are shown in Fig. 2 for men and women respectively, and the rates are also given in Table II. The male and female rates for all ages showed little change until 1954 when a slow decline began, accelerating in 1957 . These findings contrast very strikingly with the trends in death rates. The graphs for age groups show considerable variations within this general pattern.

SOURCES OF NEw CASEs.-The relative contributions of the various means of detecting new cases to the total notifications vary from area to area within the Region. However, in most areas referrals from general practitioners, either to mass radiography units or direct to the clinics, account for about half the total notifications. In the Region as a whole, the mean annual proportions in the years 1955-57 inclusive for each source of reference were as follows:

General practitioners 54 per cent. (including 18 per cent. referred to M.M.R. units);

Hospitals 19 per cent.;

M.M.R. (excluding G.P. referrals) 7 per cent.;

Contact service 10 per cent.;

Other sources 10 per cent. 
TABLE III

PULMONARY TUBERCULOSIS NOTIFICATIONS IN THE COUNTY OF WARWICKSHIRE (1951-57), BY SEX AND STAGE OF DISEASE

\begin{tabular}{|c|c|c|c|c|c|c|c|c|c|c|c|}
\hline \multirow{2}{*}{\multicolumn{2}{|c|}{$\begin{array}{lll}\text { Sex } & \cdots\end{array}$}} & \multicolumn{5}{|c|}{ Male } & \multicolumn{4}{|c|}{ Female } & \multirow{2}{*}{ Total } \\
\hline & & Minimal & $\begin{array}{l}\text { Inter- } \\
\text { mediate }\end{array}$ & Extensive & $\begin{array}{l}\text { Un- } \\
\text { classified }\end{array}$ & Total & Minimal & $\begin{array}{l}\text { Inter- } \\
\text { mediate }\end{array}$ & Extensive & $\underset{\text { classified }}{U n-}$ & \\
\hline Year .. & $\begin{array}{l}1951 \\
1952 \\
1953 \\
1954 \\
1955 \\
1956 \\
1957\end{array}$ & $\begin{array}{r}89 \\
83 \\
83 \\
119 \\
95 \\
100 \\
78\end{array}$ & $\begin{array}{r}68 \\
128 \\
117 \\
117 \\
91 \\
99 \\
73\end{array}$ & $\begin{array}{l}45 \\
34 \\
49 \\
34 \\
44 \\
45 \\
28\end{array}$ & $\begin{array}{r}37 \\
18 \\
3 \\
44 \\
29 \\
10 \\
2\end{array}$ & $\begin{array}{l}239 \\
263 \\
352 \\
314 \\
259 \\
254 \\
181\end{array}$ & $\begin{array}{r}65 \\
89 \\
104 \\
82 \\
83 \\
102 \\
72\end{array}$ & $\begin{array}{l}53 \\
72 \\
85 \\
68 \\
61 \\
36 \\
38\end{array}$ & $\begin{array}{l}18 \\
21 \\
29 \\
22 \\
15 \\
16 \\
12\end{array}$ & $\begin{array}{r}45 \\
15 \\
3 \\
11 \\
12 \\
7 \\
1\end{array}$ & $\begin{array}{l}181 \\
197 \\
221 \\
183 \\
171 \\
161 \\
123\end{array}$ \\
\hline
\end{tabular}

The mass radiography service therefore accounts for one-quarter of the new notified cases.

In considering these trends it is pertinent to examine the changing picture over the years as regards the stage of disease of newly-diagnosed cases. Such information is not available centrally for the Region as a whole, but in Table III details are given for the county of Warwickshire (pop. 550,000) for 1951-57. As regards men, the number of cases in 1956 at each stage was as high as, or higher than, in 1951, although the number of extensive cases during 1957 was much lower. With regard to women, the number of minimal cases in 1956 was much greater than in 1951, although that for 1957 was about the same; the number of "intermediate" cases decreased from 1955 to 1956 and the number of extensive cases in 1957 did not decrease noticeably.

Clinic Registers.-The number of cases on the registers of all chest clinics in the Region at the end of each year from 1948 to 1957 is shown graphically in Fig. 3. A considerable increase has taken place since 1951, and the 1957 figure exceeds that for 1951 by more than 50 per cent. However, the 1957 figure is almost the same as that for the previous year, so that this increasing trend has possibly been terminated.

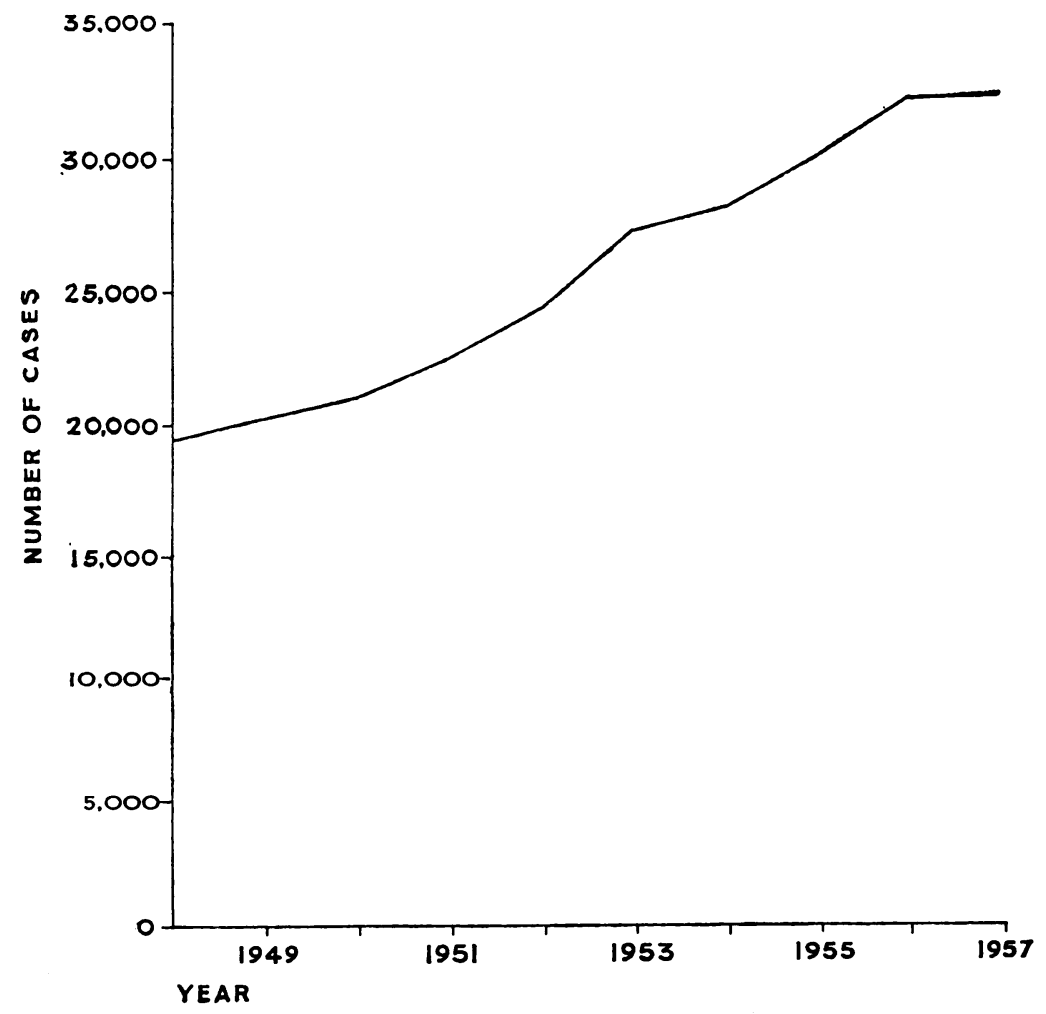

FIG. 3.-Notified cases of pulmonary tuberculosis on clinic registers. 
The continuing increase from 1951 to 1957 is undoubtedly due to the improved survival of tuberculous patients arising from new methods of treatment. The statutory follow-up period for new cases is $\mathbf{5}$ years from attaining quiescence, and in many cases it is necessary to continue supervision for even longer.

Patients with Positive Sputum.-The number of patients on the registers at the end of each year known to have had positive sputum during the preceding 6 months (1 year as from December 31, $1955)$ is shown in Fig. 4.

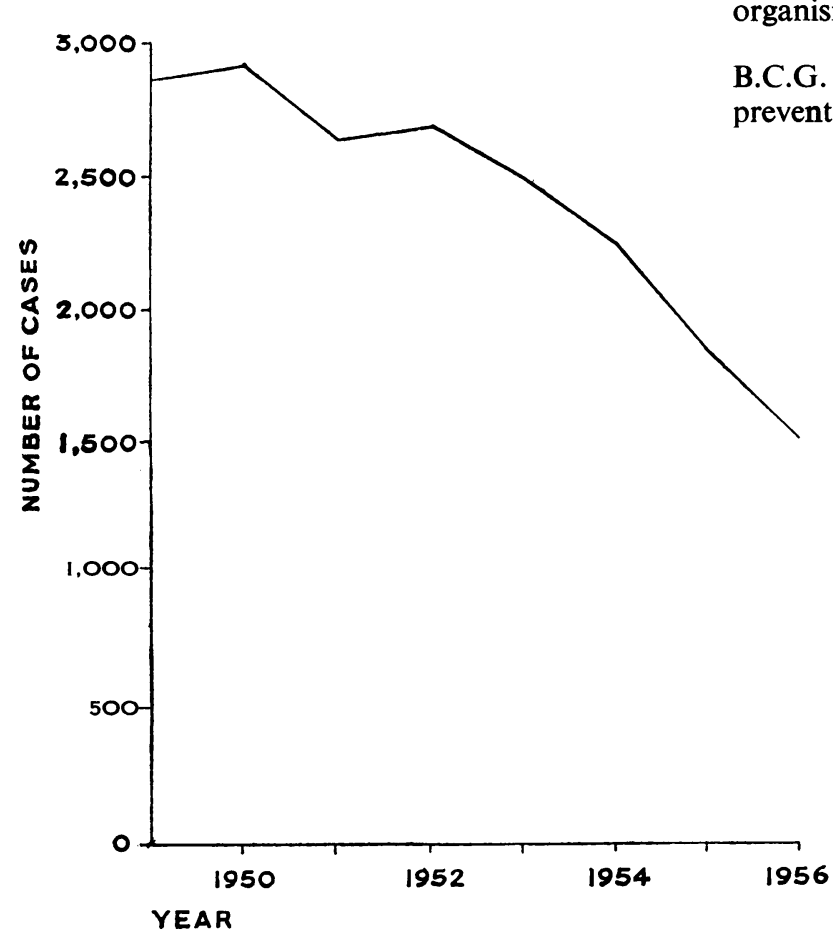
FIG.-Number of cases on clınic registers with positıve sputum (during preceding

A dramatic decrease has taken place since 1952; at the end of 1956 the total number of such patients was half that for the peak year 1950 .

It is of interest to follow up such patients to find out the numbers still infectious after a given lapse of time. Such studies have not been made on a regional basis, but the following details have been supplied by Dr. J. Aspin, consultant chest physician at Wolverhampton (pop. 150,000).

"Of 282 patients infectious in 1955, 41 were alive and sputum positive in 1957, 192 being non-infectious after treatment, 42 dead, and seven lost sight of. Of the 41 cases still sputum positive

in 1957, 26 were producing bacilli resistant to one or more of the major anti-tuberculous drugs, while fifteen were still producing fully-sensitive organisms. Of these 41 infectious cases, three were known to be at work and two of these were in the drug-resistant group."

Thus, if the experience in Wolverhampton is typical, 14 per cent. of infectious patients remain so classified 2 years later and almost two-thirds of these are drug-resistant. Different results may be obtained for different years, and it is important to find out whether these proportions are likely to change in the future, especially the proportion with drug-resistant organisms.

B.C.G. VACCINATION.-An important aspect of the preventive measures against pulmonary tuberculosis is the B.C.G. programme. It is the policy of all local authorities in the Region to vaccinate contacts, and all authorities except two have begun the vaccination of schoolleavers. In the thirteen areas with schemes operating, the percentage of children for whom skin testing and vaccination is accepted varies between 41 and 93 per cent. Most authorities with an established programme obtained an acceptance rate of at least 70 per cent. in 1957. The proportion of those tested who were negative and vaccinated during 1957 varied between 36 and 86 per cent., and in most areas the proportion was about 80 per cent.

\section{Out-Patient Services}

Chest Clinic Attendances.-Table IV shows that between 1949 and 1953 the number of new patients seen annually at the chest clinics more than doubled from 20,861 to 43,860 ; since 1953 the number of new attendances has fluctuated somewhat below the 1953 peak. The pattern for re-attendance

TABLE IV

CHEST CLINIC ATTENDANCES IN THE BIRMINGHAM REGION (1949-58)

\begin{tabular}{c|c|c|c}
\hline \multirow{2}{*}{ Year } & \multicolumn{2}{|c}{ Out-patient Attendances } & \\
\cline { 2 - 4 } & First Attendances & Re-attendances & Total \\
\hline 1949 & 20,861 & 122,011 & 142,872 \\
1950 & 29,982 & 103,603 & 133,585 \\
1951 & 33,543 & 110,262 & 143,805 \\
1952 & 37,679 & 135,333 & 173,012 \\
1953 & 43,860 & 167,319 & 211,179 \\
1954 & 41,075 & 172,455 & 213,530 \\
1955 & 35,919 & 168,350 & 204,269 \\
1956 & 39,918 & 171,606 & 211,524 \\
1957 & 39,859 & 153,035 & 192,894 \\
1958 & 38,295 & 145,666 & 183,961 \\
& & & \\
\hline
\end{tabular}


is rather similar, with an increase from 122,011 in 1949 to a maximum of 172,455 in 1954 , and numbers well below this level in 1957 and 1958.

Fig. 5 shows the total attendances at chest clinics each year, with a substantial increase between 1949 and 1954 and very little decline since. These figures are for all attendances and include contact and other routine examinations and attendances for refills. Detailed breakdown by categories is not available.

The number of new patients attending general medical out-patient clinics (including the teaching hospitals) in the Region was 57,000 a year for the years 1953-57. The total attendances (new and old) of medical out-patients was 205,000 a year over the same period, virtually the same total as for chest clinics.

In 1948 facilities for chest $x$-ray examination at the request of a general practitioner were rare or non-existent. Such services are now available throughout the Region, in some areas at the chest clinic or $x$-ray department of a hospital, in others at regular sessions by a mobile mass radiography unit, and in the City of Birmingham at a static mass radiography unit.

Mass Radiography Service.-Table V and Fig. 5 show, as for clinic attendances, a progressive increase

TABLE V

MASS RADIOGRAPHY EXAMINATIONS IN THE BIRMINGHAM REGION (1949-57)

\begin{tabular}{c|c|c|c}
\hline Year & $\begin{array}{c}\text { No. of Persons } \\
\text { Examined }\end{array}$ & $\begin{array}{c}\text { Cases of Active } \\
\text { Tuberculosis* }\end{array}$ & $\begin{array}{c}\text { Prevalence per } \\
\text { 1,000 Examined }\end{array}$ \\
\hline 1949 & 110,532 & 385 & $3 \cdot 5$ \\
1950 & 98,412 & 502 & $5 \cdot 1$ \\
1951 & 113,319 & 621 & $5 \cdot 5$ \\
1952 & 195,677 & 1,125 & $5 \cdot 7$ \\
1953 & 323,319 & 1,387 & $4 \cdot 3$ \\
1954 & 395,327 & 1,357 & $3 \cdot 4$ \\
1955 & 366,126 & 1,229 & $3 \cdot 4$ \\
1956 & 351,314 & 1,220 & $3 \cdot 1$ \\
1957 & 355,342 & 1,116 & \\
\hline
\end{tabular}

* Requiring immediate treatment or close supervision at a hospital or clinic.

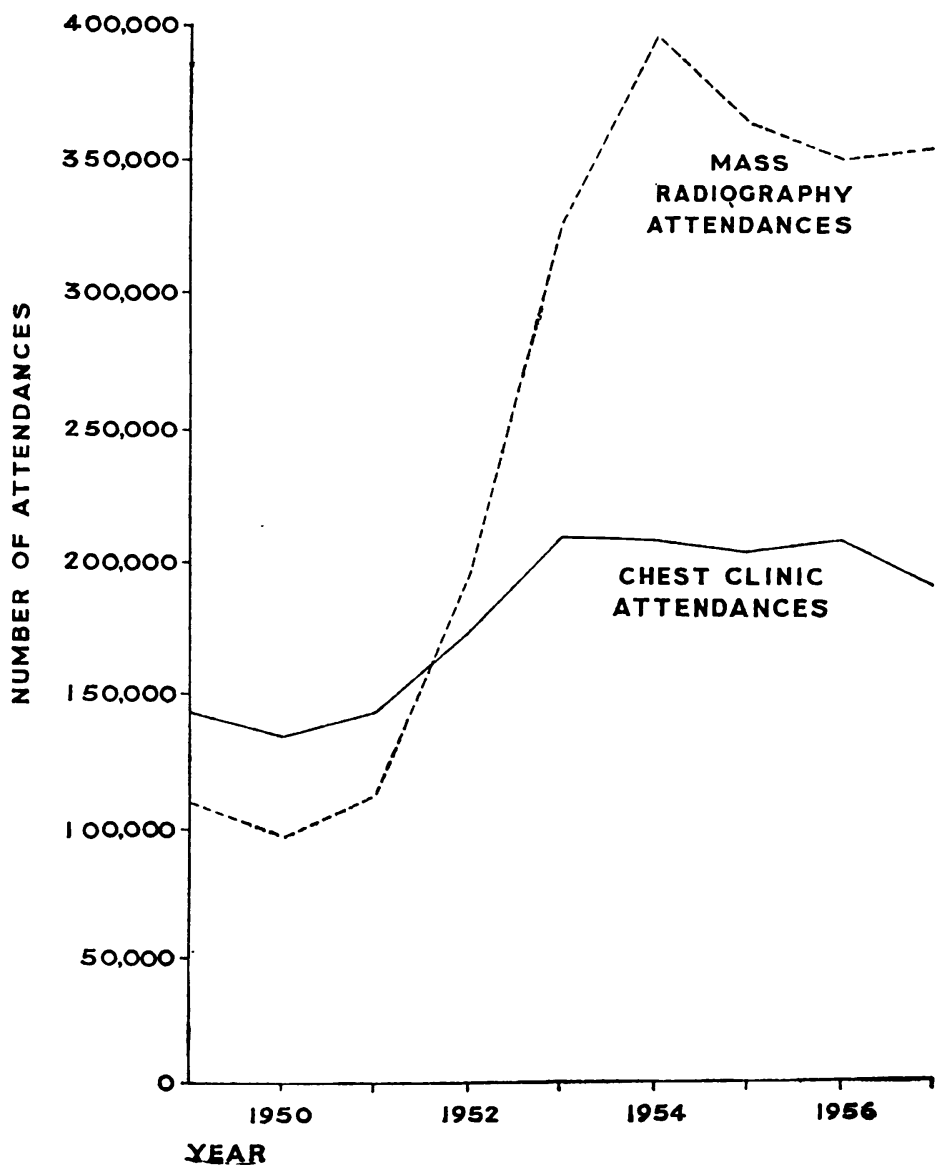

Fig. 5.-Total attendances at chest clinics and at mass miniature radiography units. 
in the annual number of mass radiography examinations from about 100,000 in 1949 to just under 400,000 in 1954, after which the figure settles at just over 350,000 . The yield of cases per 1,000 examined also increased at first, from $3 \cdot 5$ per 1,000 in 1949 to $5 \cdot 7$ per 1,000 in 1952 , with a subsequent decline to $3 \cdot 1$ per 1,000 in 1957 . Some of the increased yield in the earlier years was due to increasing proportions of high-yield groups such as general practitioner referrals. The subsequent decline must almost certainly represent a true decline in the prevalence of tuberculosis in the population, since the proportion of high-yield groups has been maintained.

\section{Out-Patient Treatment}

REFILLS.-The number of refills performed at the Birmingham Chest Clinic each year is shown in Table VI. The increase in the first 5 years may be local to Birmingham and related to changes in medical staff; the steady decline since 1953 is presumably representative of the Region as a whole, though the decline was possibly more rapid in some areas.

TABLE VI

REFILLS AT BIRMINGHAM CHEST CLINIC

\begin{tabular}{c|c}
\hline Year & Number of Cases \\
\hline 1948 & 5,000 \\
1949 & 5,250 \\
1950 & 6,000 \\
1951 & 7,850 \\
1952 & 11,500 \\
1953 & 14,040 \\
1954 & 12,000 \\
1955 & 10,080 \\
1956 & 6,240 \\
1957 & 2,412 \\
1958 & 512 \\
\hline
\end{tabular}

DomiciliaRy Chemotherapy.-Although it has not been possible to obtain figures for the whole Region, it is known that in the county of Warwickshire visits by home nurses to tuberculous households declined steadily from 1954, and in Birmingham injections of streptomycin given to patients in their homes were reduced by two-thirds between 1955 and 1958 (Table VII). The decline occurred largely because, as the waiting time before admission to hospital was reduced, there was less need to give streptomycin by injection at home; a similar change would be shown by the rest of the Region as hospital admission became easier. Much chemotherapy is still continued at home after hospital treatment is completed, but the drugs are given mainly by mouth.
TABLE VII

VISITS BY NURSES TO PATIENTS' HOUSEHOLDS, 1953-1958

\begin{tabular}{c|c|c}
\hline \multirow{2}{*}{ Year } & County of Warwickshire & City of Birmingham \\
\cline { 2 - 3 } & No. of Visits & $\begin{array}{c}\text { No. of Injections of } \\
\text { Streptomycin }\end{array}$ \\
\hline 1953 & Not Available & 60,635 \\
1954 & 21,755 & 62,156 \\
1955 & 16,918 & 63,747 \\
1956 & 12,077 & 56,586 \\
1957 & 7,418 & 31,822 \\
1958 & 4,955 & 20,381 \\
\hline
\end{tabular}

Rehabilitation.-It is impossible to obtain figures which demonstrate the changes in return to work of patients treated for tuberculosis in the past 10 years. No figures are available on a Regional basis; in the City of Birmingham the number known to have been helped in return to suitable work rose steadily from 165 in 1948 to 574 in 1956, and declined only to 501 in 1957 . This reflects the increasing number becoming fit for work as the result of treatment; it does not include those who return to their former work, and this group also is increasing. With regard to the type of work recommended, increasing numbers have been helped to return to normal industry, some after a period at the Industrial Rehabilitation Unit. The number undergoing training courses for new trades has been fairly constant at about fifty per year since 1951 .

Entries to the special Remploy Factory for tuberculous patients numbered more than 100 per year in 1950-52, but have since declined to fifty per year; individuals working there are increasingly of a chronic type, some with positive sputum and unsuitable for return to open industry. Facilities of this kind are not available throughout the Region, and in some areas ambulant chronic patients provide a special problem.

\section{In-Patient Hospital Services}

\section{Allocation and Occupation of Beds for Diseases OF THE CHEST}

Staffed allocated beds for the period 1948-57 are shown in Table VIII (opposite). An expansion programme started in 1948 added 533 beds, and by 1952 had increased the total to 2,825 . There were only minor variations in subsequent years and generally these reflected limitations imposed by a shortage of nurses until 1958 when it was planned to reduce allocated beds by 631 within 3 years. 
TABLE VIII

ALLOCATION AND OCCUPATION OF BEDS FOR DISEASES OF THE CHEST IN THE BIRMINGHAM REGION (1948-58)

\begin{tabular}{c|c|c|c|c}
\hline & $\begin{array}{c}\text { Staffed } \\
\text { Allocated } \\
\text { Beds }\end{array}$ & \multicolumn{2}{|c|}{ Average Daily Number of Beds } \\
\cline { 5 - 5 } & Available & Occupied & Unoccupied \\
\hline 1948 & 2,292 & - & - & - \\
1949 & 2,555 & - & - & - \\
1950 & 2,581 & - & - & - \\
1951 & 2,753 & - & - & - \\
1952 & 2,825 & 2,745 & 2,585 & 160 \\
1953 & 2,780 & 2,725 & 2,587 & 138 \\
1954 & 2,795 & 2,767 & 2,539 & 228 \\
1955 & 2,821 & 2,811 & 2,432 & 379 \\
1956 & 2,829 & 2,796 & 2,239 & 557 \\
1957 & 2,799 & 2,538 & 2,070 & 468 \\
1958 & 2,496 & & & \\
\hline
\end{tabular}

The medical waiting list in 1952 was 644 ; it is therefore probable that the "effective" bed occupancy was 100 per cent. The average daily number of staffed unoccupied beds for the Region was first collected in 1953, when the number was 160 . There was an annual increase in this figure from 1954 and during 1957 there was an average of 557 staffed unoccupied beds each day.

\section{RESPIRATORY TUBERCULOSIS}

WAITING LISTS.-Detailed information of the size of the regional waiting list was not available until 1952, but it is probable that in the preceding quinquennium it had steadily swollen. The maximum known figure for medical and surgical cases combined was 978 in 1952. It fell by 13, 22, 43, 71 and 25 per cent. respectively, in subsequent years. The greatest percentage fall was between 1955 and 1956, and the greatest numerical fall was 279 between 1954 and 1955. On December 31, 1958, only 44 patients were awaiting admission.

Fig. 6 shows that until 1955 occupied beds plus waiting list exceeded the staffed available beds, but since 1956 staffed available beds have been adequate so that any case of pulmonary tuberculosis may now be admitted to hospital without delay.

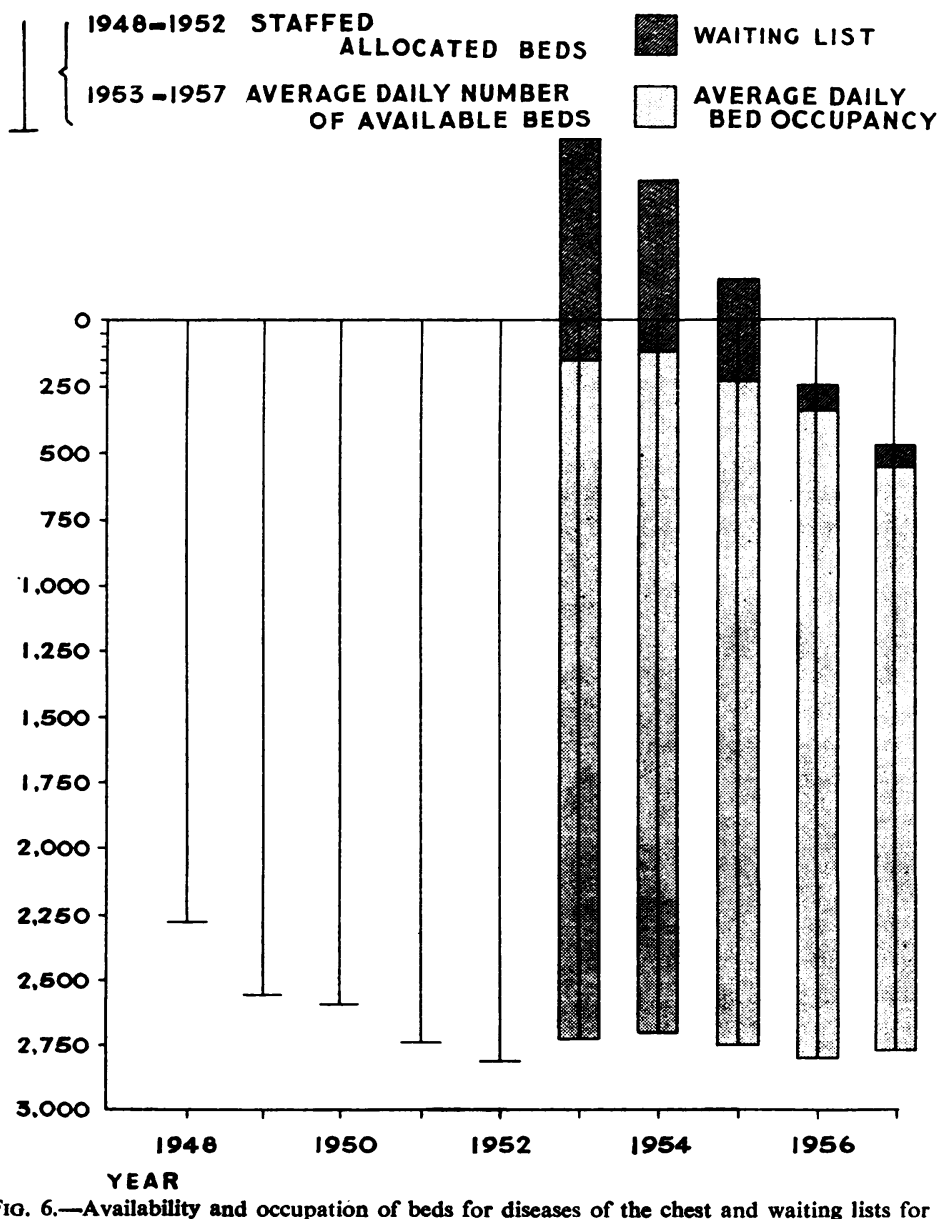
respiratory tuberculosis. 


\section{Hospital Treatment}

(1) Medical.-The majority of pulmonary tuberculosis patients start treatment in hospital. The length of stay varies considerably between hospitals but the average in regional hospitals for patients who were discharged or died in 1957 was 150 days as compared with 171 days in 1949 .

(2) Surgical.-The numbers of operations for pulmonary tuberculosis performed in the region are shown in Table IX. Surgical measures reached a peak in 1954. Thoracoplasty was painful, but safe and effective. Advances in anaesthesia enabled the development of resection, its safety being further enhanced by chemotherapeutic cover.

TABLE IX SURGICAL TREATMENT, 1949-1957

\begin{tabular}{c|c|c|c}
\hline Year & Thoracoplasty & Resection & Totàl \\
\cline { 2 - 3 } 1949 & 389 & 14 & 403 \\
1950 & 403 & 108 & 511 \\
1951 & 642 & 147 & 789 \\
1952 & 789 & 214 & 1,003 \\
1953 & 870 & 300 & 1,170 \\
1954 & 971 & 365 & 1,336 \\
1955 & 812 & 375 & 1,187 \\
1956 & 633 & 411 & 1,044 \\
1957 & 382 & 265 & 647 \\
\hline
\end{tabular}

Special Treatment Units.-Treatment in hospital of tuberculosis in certain classes of people presents special problems:

(1) Children.-The treatment of children necessitates many months in hospital and arrangements have to be made for their education. In the Birmingham Region three special units for children were developed, comprising in all 182 beds, in addition to children's units within several sanatoria.

(2) Pregnancy.-This posed difficult problems before the introduction of effective chemotherapy. Many pregnant patients with tuberculosis can now be managed without special facilities, but isolation accommodation for a limited number of infectious cases is necessary in maternity departments.

(3) Diabetes.-In patients with diabetes, tuberculosis may be extensive and at times difficult to cure. Diabetic patients need to learn the selfadministration of insulin. A Regional unit of 25 beds for this type of case was established at Romsley Hill Hospital near Birmingham, but most patients in peripheral areas are treated in a general or chest hospital by the chest physician, often in collaboration with a general physician.
(4) Patients in Mental and Mental Deficiency Hospitals. - There is evidence of a higher tuberculosis morbidity rate in mental patients than in similar groups of normal persons. The period of treatment tends to be long, and the problems of discharge connected with the mental state are often difficult. Most mental hospitals provide isolation accommodation on a limited scale; in addition a unit of 69 beds for male patients has been developed at one mental hospital to which patients can be transferred. Similarly, a special unit of 81 beds for mental defectives was set up at one of the Birmingham mental deficiency hospitals for regional use.

\section{Discussion}

The remarkable fall in tuberculosis mortality in the 10 years from 1948 has sometimes led to insufficient attention being paid to other yardsticks which may be of greater importance in planning future needs. Early in this report it was shown that the combination of rapidly declining mortality with an unchanging or slowly falling notification rate inevitably led to a substantial increase in the number of persons on the live tuberculosis register, all needing regular supervision. This in part explains the increase in the number of re-examinations at chest clinics, the other cause being the need for regular supervision at reasonably short intervals of patients who have started chemotherapy at home because of an insufficient number of beds in hospital. In the last 2 or 3 years, however, waiting lists have declined and disappeared, so that all patients who need it can now start their treatment in hospital. Regular review of bed requirements will be necessary in future, though it is essential from the public health aspect to ensure that an adequate number of beds for the prompt admission of all tuberculous patients is available.

From the epidemiological aspect the decline in the number of patients with positive sputum represents a real advance, though the proportion with resistant organisms is a feature which gives rise to anxiety. The greatly increased use of B.C.G. vaccination in the past 5 years should soon produce results by reducing the number of new cases in young adults, though this measure must be regarded as a long-term cumulative investment rather than as one which can produce rapid results.

The majority of new cases of tuberculosis are still identified through general practitioner referrals, either for " $x$ ray only" or for normal consultative 
sessions. The mass radiography service is, however, responsible for an appreciable number of new diagnoses which could be made in no other way at that stage of the disease; their work will need to continue on an undiminished scale, though it is to be hoped with a diminishing return, and the use of some units for intensive community surveys has been instituted. The increasing provision of " $x$ ray only" sessions for general practitioners is probably responsible for the recent small decline in the number of new attendances at chest clinics.

On the hospital side the major change has been from enormous waiting lists to the existence of some empty beds and to a reduction in the number of beds allocated to tuberculosis. There has also been a great decline in the number of surgical operations for tuberculosis. It has often been difficult to find sufficient nursing staff for the available beds, and the very effectiveness of treatment has tended to increase this by tending to make the work less interesting because of its apparent simplicity, and also by reducing the number of ex-patients who have taken up nursing in sanatoria because they were not fit enough to return to their original work.

Whilst steady progress in anti-tuberculosis work is being made, the present situation of an infectious disease of which over 3,000 new cases are notified in the Region each year cannot be regarded as satisfactory. Other features which indicate that there is still much to be done are the absence of any fall in the number of deaths from tuberculosis of patients not previously notified, the number of patients sputumpositive with resistant organisms, and the fact that in 1957 at least 13 per cent. of children have been infected with tuberculosis by the age of 13 years. It has recently been said that tuberculosis will have been eliminated as a critical public health problem when no more than 1 per cent. are infected by the age of 14 years.

\section{SUMMARY}

(1) In the Birmingham Hospital Region, the mortality rate from pulmonary tuberculosis in men declined from 52 per 100,000 in 1948 to 17 in 1957; in women it declined from 29 to 4 per 100,000 in the same period.

(2) Notification rates for pulmonary tuberculosis in men declined from 125 per 100,000 in 1948 to 83 in 1957 ; in women they declined from 81 to 51 per 100,000 during the same period.

(3) As a result of rapidly declining mortality and slowly declining notifications, the numbers of persons on the respiratory tuberculosis registers in the Region have increased from 19,459 in 1948 to 31,828 in 1957. The number of these patients known to have had tubercle bacilli in their sputum in the previous 6 months declined from 2,875 in 1949 to 1,516 in 1956.

(4) At least half of all new notifications were made as a result of patients reporting symptoms to their general practitioners. The contact service and mass radiography (excluding general practitioner referrals) each contributed about 10 per cent. of all notifications.

(5) B.C.G. vaccination has been introduced into the Region in the past 10 years; it is extensively used for contacts, but its use among 13 to 14-year-old schoolchildren varies from nil in some areas to a more than 80 per cent. acceptance rate in other areas.

(6) Total attendances at chest clinics in the Region rose from 142,872 in 1949 to 213,530 in 1954 and have since remained at about 200,000 per annum; the pattern has been similar for first attendances and for re-examinations, but with a rather greater proportional increase in first examinations than in re-examinations.

(7) Examination by mass radiography units increased from 110,532 in 1949 to 395,327 in 1954 and thereafter continued at over 350,000 per annum. Increasing provision has been made for $x$-raying patients at the request of general practitioners.

(8) Artificial pneumothorax and pneumoperitoneum have virtually disappeared as methods of treatment, and the many thousands of refills previously done each year are now no longer needed. Domiciliary chemotherapy, including streptomycin injections in the home, reached a maximum in 1954-55; the use of streptomycin in the home has since declined very considerably.

(9) Staffed hospital beds allocated for the treatment of tuberculosis and diseases of the chest increased from 2,292 in 1948 to 2,829 in 1956, and were slightly reduced in 1957 . There was a further substantial reduction in 1958.

(10) The waiting list for admission to hospital for treatment of tuberculosis totalled 978 in 1952 (the earliest year for which the figure is available). The waiting lists subsequently declined substantially, and at the end of 1958 only 44 patients were awaiting admission; considerably more than this number of staffed allocated beds were then unoccupied.

(11) Major surgical operations for the treatment of pulmonary tuberculosis increased from 403 in 1949 to 1,336 in 1954 , and then declined to 647 in 1957. 